Article

\title{
Developing Joint R\&D Institutes between Chinese Universities and International Enterprises in China's Innovation System: A Case at Tsinghua University
}

\author{
Jinyuan Ma®
}

Center for Higher Education Research, Southern University of Science and Technology, Shenzhen 518055, China; majy@sustech.edu.cn

Received: 9 October 2019; Accepted: 9 December 2019; Published: 12 December 2019

\begin{abstract}
This paper examines the role of joint R\&D institutes co-established by Chinese research universities and international enterprises. Guided by an analytical framework of institutional logics in the evolution of the Triple Helix model, this study aims to explore the institutionalization process of a joint R\&D institute in the contexts of global and Chinese innovation systems; further, it analyzes which mingling institutional logics, respectively carried by a Chinese research university and an international enterprise, affect the collaboration between both parties moving from informal R\&D collaboration toward an institutionalized organization. The case study method enabled the author to understand the complexity of the interlacing of international and national actors with regards to the joint R\&D institutes. The contribution of the study to the existing literature is two-fold: on the conceptual front, it advances theoretical understandings of the interactions of institutional logics which result in varied patterns of joint $R \& D$ institute in a national context with transnational factors; on the empirical front, it examines the evolutionary path of a joint $R \& D$ institute established by a Chinese research university and an international enterprise.
\end{abstract}

Keywords: joint R\&D institute; institutional logics; China's innovation system; China's transnational Triple Helix linkages; Chinese research university

\section{Introduction}

In the contemporary era of R\&D globalization, when knowledge, technology and human resources are becoming globally and geographically distributed, many research-intensive universities are increasingly engaged in R\&D partnerships with international enterprises [1]. Joint R\&D institutes are an important form of partnership taking place between research universities and international enterprises [2,3].

The key term of this study, joint R\&D institute, originates from the broadly defined concept of cooperative research center [4-9]. The term "joint R\&D institute" is used alternatively in this study in order to highlight the contextual relevance of Chinese research universities, as the names of China's university-based cooperative research centers always start with "joint" (Lian He in Chinese) Joint R\&D institute in this paper is defined as:

An organization or unit, jointly established by a research university and an international enterprise, that have officially registered in the university's research management department with explicit missions to promote, directly or indirectly, cross-sector and cross-border collaboration, knowledge and technology transfer, and ultimately innovation $[6,10]$.

In this study, the joint $R \& D$ institutes refer to the cooperative research centers jointly established by Chinese research universities and international enterprises. They share the three common features with the cooperative research centers, which are identified by Boardman and Gray (2010: 451): (1) engagement 
in research, (2) exhibition of organizational formality, and (3) promotion of organizational and cross-sector collaboration and transfer. In this study, the above-mentioned "larger organization" refers to the joint $R \& D$ institute's affiliated university. The joint $R \& D$ institutes' mandates, operations and activities reflect the interests of both their affiliated universities and their external international sponsors. Moreover, their organizational formalities are more flexible than departmental structures and can be adjusted to increase the universities' adaptations and responsiveness to the demands of the external community $[11,12]$.

Since the mid-1990s, when an increasing number of international enterprises started to move better paid and more brain-intensive labor to China, Chinese research universities have become the primary R\&D partners for these enterprises [13-15], and joint R\&D institutes have become one of their most important forms of partnership [16-19]. As of 2016, international enterprises had established more than 1800 R\&D institutes in China [20]. According to statistics from the Ministry of Education of China, the key universities directly under the supervision of the Ministry of Education have close collaborations with more than 1100 enterprises from more than 100 countries around the world [21].

What, then, are the attractions of China, and the Chinese research universities, for those international enterprises? Wang et al. [22] perceived R\&D cooperation as a kind of transaction. The major incentives for international enterprises are pressure from market competition and cost saving. Universities provide knowledge and cultural products as well as human resources to enterprises, while enterprises can supply universities with funds, equipment, and information about market needs for talents. Xue (2006) [23] provided a similar opinion: owing to the favorable research platforms offered by joint R\&D institutes, international enterprises can easily synergize internal and external $R \& D$ resources, lower their development costs through avoiding transaction costs, reduce the risk of project failure due to better interaction, and acquire promising graduates from Chinese universities.

Cong and Xue [24] discussed the international enterprises' strategic planning from the perspective of integrated innovation, which means integrating, coordinating and optimizing interrelated, interdependent and interactive innovation elements to achieve the specific purpose of efficient innovation. The reason why international enterprises have decided to cooperate with Chinese research universities in the rapidly growing technological field is to reduce the risk brought by remarkable technological change. They want to trace the new direction of universities' basic and applied research, and to be prepared to effectively integrate newly developed technologies with existing ones. Therefore, when R\&D cooperation involves technological exploration that is closely bound up with the enterprises' development strategies, the enterprises will attach much attention to process and result management.

He [25] believes that, besides acting as the nodes of international enterprises' global R\&D expansion, joint R\&D institutes can also become involved in enhancing the universities' independent innovation capacity and disciplinary development level, as well as serving as an interface for technological cooperation and knowledge exchange between universities and international enterprises.

Besides the intentional initiatives undertaken by international enterprises, behind the intensity of R\&D partnerships lies the Chinese government's "invisible hand" [26]. China's prioritization of innovation since the second half of the 1990s, and the country's desire to acquire knowledge and technology, have provided important opportunities and vehicles for technology-intensive international enterprises to exploit their innovation activities in China $[18,27,28]$. Specifically, these include China's rapidly rising $R \& D$ expenditure, a larger and higher-quality talent pool, comparatively low-cost researchers, and an impressively growing number of scientific publications and patents [18,29]. When discussing the "invisible hand", Xue (2006) [23] stated that support from the Chinese government, in terms of policies and public funding, has been important for promoting joint R\&D activities.

Joint $R \& D$ institutes are positioned as the most mature form of R\&D partnership between Chinese research universities and international enterprises [19,21]. Li and Li [19] classified the forms of R\&D collaboration into project commission, joint development, joint talent training, and joint R\&D institutes. Huang [21] also made such a classification in terms of development stages: personnel exchange and 
academic visits, international academic conferences, joint research, joint research programs, and joint R\&D institutes.

When enterprises and universities seek $R \& D$ partners then the joint $R \& D$ institutes, as long-term cooperative research platforms, should be established based on a strong complementarity of advantages [30,31]. Specifically, Gugler and Michel [32] argued that these partnerships should follow " $4 \mathrm{C}$ " principles: complementary ability, cooperative culture, compatible objectives, and commensurate risks. When choosing locations, international enterprises prefer major cities with a strong presence of international investors, and universities with distinct disciplinary advantages and strong $R \& D$ capacities; the enterprise side should have a corresponding capacity for technological development, applied research, and technology transfer [31].

With regards to the adoption of cooperative modes, Wright et al. [33] classified the activities of joint $R \& D$ institutes into three stages: in the first stage of technological invention, a joint development model should be created; in the second stage of technological adaptation to the market, entrusted development can be the cooperative model; and in the third stage of technological diffusion, universities should provide advisory services to industries. According to Mowery and Sampat [34], entrusted development is a more important model than patent licensing and technology transfer in joint $R \& D$ activities.

Empirical investigations have revealed problems in the R\&D partnerships in joint R\&D institutes. Some studies have recognized the unequal status between Chinese universities and international enterprises as $R \& D$ partners. The international enterprises often take a dominant position in intellectual property right (IPR) ownership distribution [35], R\&D orientation [36], and institutional management $[37,38]$. Some IPRs involving core technology are exclusively monopolized by international enterprises [39]. The unequal situation often reflects which side is the funding provider and unequal $R \& D$ strength, although the advantageous $R \& D$ strength of international enterprises also has a positive impact on the universities' R\&D improvement [17].

However, a gap in R\&D experience between partners [40], as well as skills for knowledge and technology application and innovation, can reduce the efficiency of technology and knowledge spillover [41]. Moreover, a lack of communication skills and channels has been identified. First, this problem has impeded the ability of university R\&D management staff to obtain R\&D management experience [42]; second, this may lead to deficiencies in prior agreements [40]; third, when misunderstandings or disputes take place within the partnerships, the lack of resolution mechanisms may result in obstruction of technology spillover [43].

Despite all these problems, the positive effects of R\&D cooperation on Chinese universities have also been remarkable in terms of financial support and upgrades to R\&D strength [44]; in particular, $R \& D$ cooperation has helped university researchers better understand the trends of large international enterprises' product and technology innovation in China. In addition, it can expand the university researchers' forward-looking and cutting-edge views in the field, which can better match the market's orientation [45].

As discussed above, establishing joint $R \& D$ institutes is really an emerging and flourishing phenomenon in China, and there is a general research challenge on the organizational analysis of such kinds of organizations. Nevertheless, the existing literature points out that the nature of joint $R \& D$ institutes between Chinese universities and international enterprises is concerned with a mix between Chinese and Western ways of organizing things. The organizing principles can be understood as institutional logics, which are "the shared conceptual and normative frameworks that provide guidelines for the behavior of field participants" [46] (p. 8). The literature also implies that specific features of joint $R \& D$ institutes and challenges in running such institutes are related to the nature. However, few studies have provided theoretical accounts of the nature of mixing logics of underlying joint $R \& D$ institutes, particularly in explaining how the mixed institutional logics have affected the development of the joint R\&D institutes.

Related to the lack of theoretical understandings of joint R\&D institutes, another gap is that the research on joint $R \& D$ institutes focuses much on issues within the organizational boundaries 
of joint R\&D institutes, with little attention to the contexts in which the joint R\&D institutes are embedded. As suggested by Cai et al. [47], the contexts involved in transnational university and industry collaboration can be understood as transnational innovation eco-systems. As one of the rare studies taking a macroscopic and systemic point of view when researching joint R\&D institutes, Xue and Wang [45] argue that joint R\&D institutes have acted as the nodes in the transnational innovation systems. These joint R\&D institutes represent a new type of actor in China's innovation system, which has made the national boundary of the system vaguer. Their study not only confirms that a fundamental characteristic of joint $R \& D$ institutes is a hybrid of institutional logics but also implies that multiple institutional logics in the joint R\&D institutes may derive from system levels of logics of both China and forcing countries, from which the collaborating enterprises come. However, there is no ready framework for understanding the influences of the system logics on the development of joint R\&D institutes.

To bridge the gaps, this paper aims to build an analytical framework to understand the development or institutionalization of joint R\&D institutes and apply the framework in an empirical case of Tsinghua University's collaboration with an international enterprise in developing a joint R\&D institute. Meyer and Rowan [48] (p. 341) define institutionalization as a process "by which social processes, obligations, or actualities, come to take on a rule-like status in social thought and action". This paper seeks to probe what specific features of institutionalization raise collaboration from an informal international $R \& D$ partnership to a joint $R \& D$ institute, and what kinds of supportive environments lead to the development.

The framework used in this study is based on Cai $[49,50]$ who used an institutional logics perspective to interpret the evolution of the Triple Helix model at the system level. The framework is relevant to this research for two reasons. First, the joint R\&D institutes to be discussed in this paper act as hybrid organizations actively operating at the interfaces between the central government, research universities, and international enterprises [26,49,51]. Second, the institutional logics perspective provides an analytical tool to explain the outcome of a process with a certain length of time and to understand the influences of broader social and cultural norms on the cognition and behavior of individuals and organizations [52]. However, since Cai's framework itself is on the analysis on the system level, it will be revised for the use in organizational level analysis.

A joint R\&D institute established by Tsinghua University (Tsinghua) and the United Technologies Corporation (UTC), i.e., the Tsinghua-UTC Research Institute for Integrated Building Energy, Safety and Control Systems, was adopted as the case in this research. UTC is an American multinational conglomerate. It researches, develops, and manufactures high-technology products such as aircraft engines, helicopters, HVAC, fuel cells, elevators and escalators, fire and security products, building systems, and industrial products, among others. UTC is also a large military contractor, producing missile systems and military helicopters, most notably the UH-60 Black Hawk helicopter. (https://en.wikipedia.org/wiki/United_Technologies. (Accessed on 10 November 2019)). Based on a review of the relevant academic literature, the major data source chosen was semi-structured and in-depth interviews (conducted during the periods of 2013-2014, and 2018; $\mathrm{N}=15$ ). The interviewees included researchers and administrative staff of the case institute, the university-level administrative staff of Tsinghua (who were responsible for university-industry cooperation or international cooperation), and administrative staff of UTC (who were taking care of university-industry collaboration).

Specifically, this paper seeks to probe the research question: what mingling institutional logics respectively carried by Tsinghua University and the UTC affect the collaboration between both parties moving from informal collaboration toward an institutionalized organization? Based on the research findings, the paper will solicit recommendations to policymakers and practitioners involved in joint R\&D institutes between Chinese universities and international enterprises.

The contribution of the study to the existing literature is two-fold: on the conceptual front, it advances theoretical understandings of the interactions of institutional logics which result in varied 
patterns of joint $R \& D$ institutes in a national context with transnational factors; on the empirical front, it examines the evolutionary path of a joint $R \& D$ institute established by a flagship Chinese research university and an international enterprise.

\section{Methodology and Case Selection}

A case study stood out as the method of choice for this study $[53,54]$. Firstly, the selected method enabled the author to understand the complexity of the interlacing of international and national actors with regards to the joint R\&D institutes; secondly, it enabled the author to understand the institutional environment and contextual relevance of the joint R\&D institutes operating in China's transnational Triple Helix linkages and in China's innovation system.

The case of the Tsinghua-United Technology Corporation Research Institute for Integrated Building Energy, Safety and Control Systems (the Tsinghua-UTC Center) was selected, taking account of the following criteria:

- It was a research institute officially affiliated with Tsinghua University, rather than merely being located on the campus [55];

- It was a joint R\&D institute co-established by Tsinghua University and an international enterprise;

- It was semi-autonomous from a traditional disciplinary department (an optional criterion) [56];

- The researchers of the institute were from more than one disciplinary department, and it conducted interdisciplinary research (also an optional criterion) [6,57].

The rationales for selecting the case of the Tsinghua-UTC Center affiliated with Tsinghua University were as follows:

As a flagship Chinese research university, Tsinghua bears the brunt of the responsibility for achieving the objectives of governmental higher education or science and technology programs [58]. On the other hand, it has been given priority to enjoy intensive governmental R\&D investment. Geographically, socially, and politically, Tsinghua has the closest connections with the central government, in particular with the Ministry of Education (MOE) and the Ministry of Science and Technology (MOST) [59].

The abundant financial and human $R \& D$ resources possessed by research universities like Tsinghua have been a significant precondition for large international enterprises to co-establish joint R\&D institutes with them [60]. Tsinghua has been among the most popularly targeted Chinese research universities when international enterprises consider R\&D partnerships in China (Interview THU UA 2).

Moreover, Tsinghua possesses high-quality multi-disciplinary researchers. A majority of them have overseas education or working experience. This has guaranteed the human resources of the international and interdisciplinary joint $R \& D$ institutes [61]. The researchers of Tsinghua have always taken the lead in various forms of international R\&D cooperation and university-industry partnerships [59].

The case study of the Tsinghua-UTC Center was conducted by the author in 2013-14 on the basis of a literature review and fieldwork. In addition to publicly accessible information, including the official websites of Tsinghua, the Ministry of Education (MOE), the Ministry of Science and Technology (MOST), and the National Bureau of Statistics of China, and the brochure of the Tsinghua-UTC Center, semi-structured interviews were the major source of evidence in the study.

The participants in the study can be categorized as follows:

(1) Group One: members of the Tsinghua-UTC Center. Four Tsinghua researchers (one professor, one associate professor, one post-doctoral fellow, and one postgraduate research student); one marketing staff member from the UTC; and one administrative staff member of the Center;

(2) Group Two: three university-level administrative staff members of Tsinghua, who oversaw the university-industry cooperation, international cooperation, and disciplinary planning;

(3) Group Three: one government official from the MOE and two from the MOST; 
(4) Group Four: five external observers, scholars who were specialized in the fields of the internationalization of higher education, university-industry linkage, Chinese higher education transformation, and Chinese higher education policy.

\section{Analytical Framework}

The fundamental assumption underlying the analytical framework to be developed in this paper for understanding the influences of mingling institutional logics at the system level for the development of joint R\&D institutes is that the joint R\&D institutes are in the contexts of mixing institutional logics in both China's innovation system and a global (Western) innovation system (as illustrated in Figure 1). Chinese universities carry the logics from China's innovation systems and the Chinese university's collaborating international enterprises and joint R\&D institutes carry institutional logics from Global (Western) innovation systems. When analyzing the contextual influences on the evolution of joint R\&D institutes, the following elements are needed: (1) a framework for analyzing institutional logics in innovation systems, (2) differences between disparate institutional logics in Global and China's innovation systems, and (3) a framework for understanding the evolution of joint R\&D institutes. The three aspects are introduced in this section and then integrated into the analytical framework.

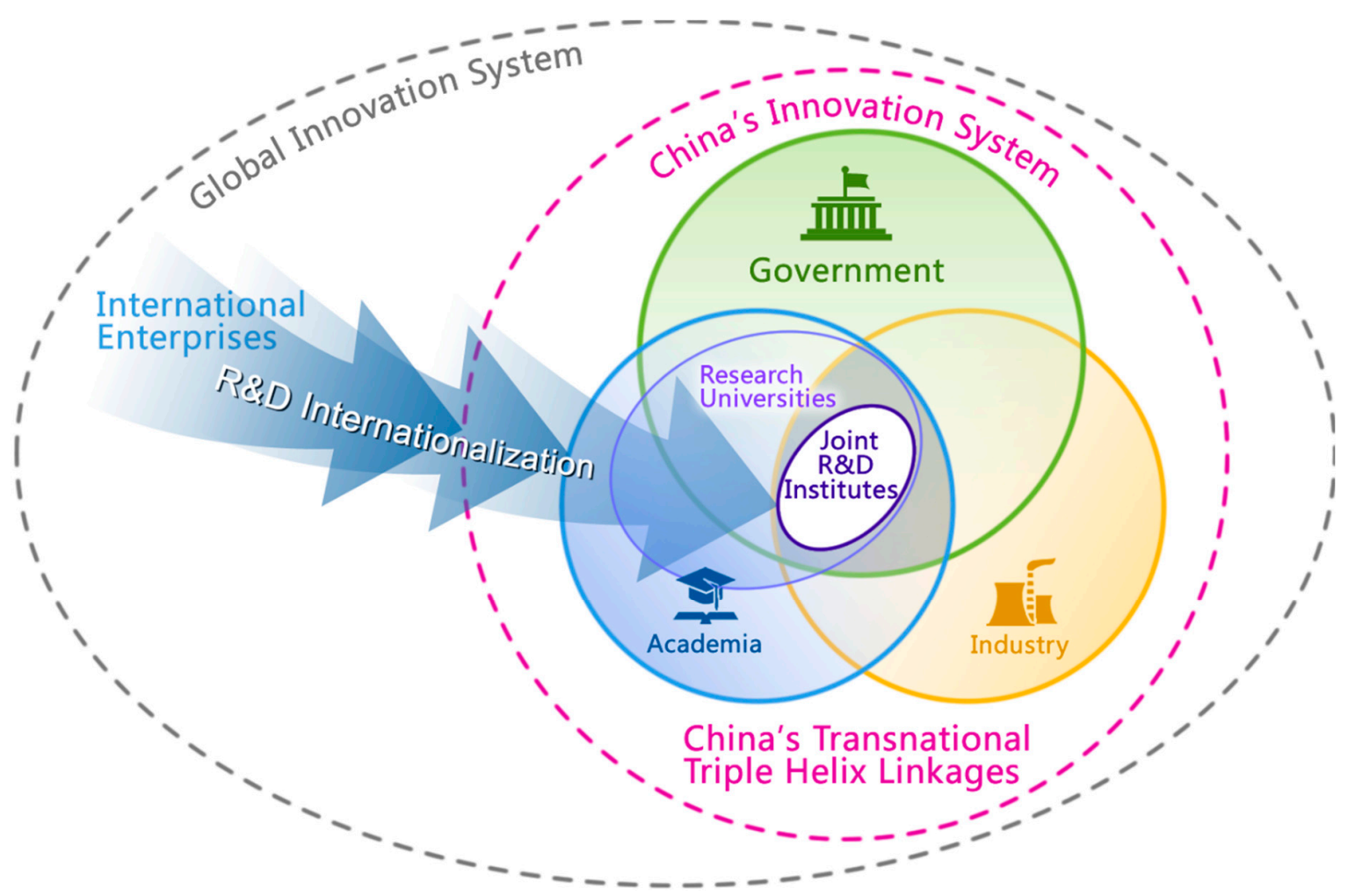

Figure 1. Joint R\&D institutes in the context of global and China's innovation systems.

\subsection{Institutional Logics in Innovation Systems}

When understanding institutional logics in innovation systems, this study adopts Cai [49,50], who understands innovation systems from the perspective of Triple Helix Model, and identifies seven institutional logics aligned with an ideal Triple Helix model. The "ideal model", together with the "statist model" and the "laissez-fair model" were classified by Etzkowitz and Leydesdorff [62] as the three major types of Triple Helix models. In the statist model, the government encompasses university and industry, and decides the relationships between them; it is expected to take the lead in innovation initiatives and provide resources for these new projects. The laissez-faire model defines the three helices as different communication systems with strong borders dividing them and highly circumscribed relations among the spheres [49,63]. In the ideal model, in addition to its traditional 
function, each helix undertakes the roles of the others. Government devolves the role of regional and local innovation coordinator to the other two actors: i.e., industry engages in endogenous technological innovation and transfer, or industrial R\&D laboratories emerge in universities; in response to the changes, universities not only play an innovative role in traditional basic research, but also in applied research, entrepreneurial training and community building $[49,63,64]$. This is said to be an ideal model which represents a global tendency in innovation systems [63].

Institutional logics can be generally understood as "the socially constructed, historical pattern of material practices, assumptions, values, beliefs, and rules by which individuals produce and reproduce their material subsistence, organize time and space, and provide meaning to their social reality" [65] (p. 804). The institutional logics in certain contexts will explicitly affect the communication paradigms of different stakeholders, and determine prioritized problems and appropriate solutions [52].

Cai associates the seven institutional logics with four stages of institutionalization of Triple Helix development $[49,50,66]$ (Table 1 ). This framework can be used for comparing institutional logics differences between Chinese and Western innovation systems.

Table 1. Institutional logics in the evolution of the Triple Helix model.

\begin{tabular}{|c|c|c|}
\hline Stages of Development & Major Triple Helix Activities & $\begin{array}{l}\text { Favorable Institutional } \\
\text { Logics }\end{array}$ \\
\hline $\begin{array}{l}\text { Stage } 1 \\
\text { Realization of the needs }\end{array}$ & $\begin{array}{l}\text { Realizing the importance of entering a } \\
\text { reciprocal relationship between } \\
\text { university, industry and government }\end{array}$ & $\begin{array}{l}\text { Shared beliefs on knowledge } \\
\text { as a key to economic growth }\end{array}$ \\
\hline $\begin{array}{l}\text { Stage } 2 \\
\text { Intra-organizational } \\
\text { transformation }\end{array}$ & Taking the role of the other & $\begin{array}{l}\text { Market orientation } \\
\text { Process management }\end{array}$ \\
\hline $\begin{array}{l}\text { Stage } 3 \\
\text { Interactions between } \\
\text { organizations in the three sectors }\end{array}$ & $\begin{array}{l}\text { Growing and innovating through } \\
\text { cooperation with others } \\
\text { Generating hybrid organization }\end{array}$ & $\begin{array}{l}\text { Effective IPR Protection system } \\
\text { Civil society }\end{array}$ \\
\hline $\begin{array}{l}\text { Stage } 4 \\
\text { Institutionalization of the Triple } \\
\text { Helix model }\end{array}$ & $\begin{array}{l}\text { Feedback loops between policy-makers } \\
\text { and participants } \\
\text { Institutionalized norms of } \\
\text { "entrepreneurial university", } \\
\text { "knowledge-based formation and } \\
\text { growth" and "innovation state" [26]. }\end{array}$ & $\begin{array}{l}\text { Competitive market } \\
\text { Democratic policymaking }\end{array}$ \\
\hline
\end{tabular}

In Stage 1 of the "ideal" model, the belief that the logic of technology advancement/innovation is the key to economic growth is shared by government, industry and university. In Stage 2, the logics of market orientation and process management will facilitate intra-organizational transformation in the process of 'taking the role of the other'. In Stage 3, The logics of IPR protection affect the efficiency of technology transfer from university to industry. In countries lacking a civil society, there often exists the statist model of Triple Helix, in which the state takes overall coordination responsibility and thus provides only a limited source of ideas and initiatives [68] (p. 62). In Stage 4 of the "ideal" Western model, the logics of competitive market and democratic policymaking can realize the best choices to engage in tripartite interactions, and eventually institutionalize the optimum model in the Western context [50] (p. 18).

\subsection{Chinese Triple Helix System}

The Triple Helix model in China was interpreted by Zhou [69] as a "government-pulled Triple Helix model": the state plays a central role in the innovation processes; the R\&D resources are mostly derived from the government; universities and industries may lose initiative and flexibility in innovation; university-industry joint R\&D projects tend to be "shows" for the government. Given such a context, China's Triple Helix model had long been categorized in the statist group $[63,64,70]$. Despite this 
common belief, a statist model is not the only one pertinent to China's national innovation system, given China's immensity and diversity [67]. The situation has been changing over the past two decades, and a transitional tendency from a statist to an ideal model has been acknowledged in the Chinese case.

Recent studies by Cai and Liu [71,72] challenge the conventional view of seeing China as a statist Triple Helix model. They found a variety of Triple Helix models in Chinese regional innovation systems by taking into account of multiple layers of government, e.g., central government, municipal government and district government, in a Triple Helix analysis. In the case of Tongii University Creative Cluster, they found an effective Triple Helix model, combining both bottom-up initiatives in the initial stage and top-down coordination in later developments [71].

The transition of China's Triple Helix model was demonstrated by an OECD study completed in 2008 [73]. The core ideas of this transition are: the governmental batons have started to become invisible; the spiral of academia works more closely with industries; in particular, the government has become increasingly supportive of the enhanced role of universities in assuming a "third mission" in addition to their traditional functions of teaching and research $[29,67,73]$.

Overlapping institutional spheres, the main element of the ideal model, have emerged, which have gradually become the core of various innovation systems due to the advantages of their networked infrastructures in terms of social benefits, economic efficiencies, and sustainability $[26,51,64,74]$. They have been expected to create knowledge spillover and to contribute to the capacity of innovation systems $[26,51,75]$.

Joint R\&D institutes, as hybrid organizations, are incubated in the knowledge infrastructure of these overlapping institutional spheres. Their flourishing in Chinese research universities, from this angle, can certify the transition of China's Triple Helix model.

\subsection{The Collision of Western and Chinese Institutional Logics}

It has been understood that the ideal Triple Helix model has been advanced from the Western experience of economics, and it is called "ideal" as it has been proven by a number of empirical cases in Western societies that the overlapping and interdependency between the three sectors provides favorable conditions for innovation. The ideal model was initially developed and has been institutionalized in Western societies, thus the institutional logics that facilitate the institutionalization process are Western-oriented [49,76-78]. When the ideal Western Triple Helix model is applied in China's innovation system, a non-Western context, the logics associated with the ideal model are likely to be imported as well [50].

However, there is a lack of theoretical consideration and empirical evidence on whether the ideal Triple Helix model is ideal for China, as the local institutional logics of the Triple Helix model in China are different from those in the West [49]. Moreover, the institutional logics of non-Western Triple Helix models, such as the China-specific one, may result in more obstacles to a favorable innovation environment compared to the institutional logics of the ideal model in Western countries [67]. The establishment and evolution of joint R\&D institutes by Chinese research universities and their "Western industrial partners" may result in collisions between Chinese and Western institutional logics. Taking account of the China-specific social relevance and settings, the collisions have the potential to interpret the challenges and dynamics of developing different models of Triple Helix linkages in the context of China's innovation system.

\subsection{Institutionalization of Joint RED Institutes}

Although in Cai's $[49,50]$ analytical framework the institutional Triple Helix model is on the innovation system level, the evolution of an innovative organizational model of joint R\&D institutes can also be understood as a process of institutionalization [79]. When identifying the four stages of Triple Helix development, Cai [50] is based on the common notions of the stages of the institutionalization process, basically including three stages: "first, organizational actors realize there is a need for change; then they initiate organizational changes; and finally the changes either become institutionalized or 
are terminated" [50] (p. 306). The broader social and cultural norms of innovation systems that make changes to organizational patterns of joint R\&D institutes and persist in time belong in the institutional order [80]. This study attempts to probe the outcome of an evolutionary process which is subject to the broader conditions of certain contexts rather than focusing exclusively on organizational features of joint $R \& D$ institutes. It is thus justified to choose the institutional perspective for this study.

\subsection{Integrated Analytical Framework}

The establishment and evolution of joint R\&D institutes co-established by Chinese research universities and their "Western industrial partners" may result in collisions between Chinese and Western institutional logics. Thus, we need an integrated framework to link the macro and micro level of analysis. Based on synthesising the theoretical insights discussed above, the following analytical framework is constructed in Table 2.

Table 2. Institutional evolution of joint R\&D Institutes co-established by Chinese research universities and international enterprises.

\begin{tabular}{|c|c|c|c|}
\hline $\begin{array}{l}\text { Stages of } \\
\text { Development }\end{array}$ & Description of the Stage & $\begin{array}{l}\text { Mingling Institutional Logics } \\
\text { (Tensions vs. Reconciling) }\end{array}$ & $\begin{array}{l}\text { Influences of Mixing } \\
\text { Institutional Logics on the } \\
\text { Development of Joint R\&D } \\
\text { Institutes }\end{array}$ \\
\hline $\begin{array}{l}\text { Stage } 1 \\
\text { Realization of } \\
\text { the needs }\end{array}$ & $\begin{array}{l}\text { Chinese government, } \\
\text { university, } \\
\text { and international } \\
\text { enterprise realize the } \\
\text { needs for transformation } \\
\text { and interaction }\end{array}$ & $\begin{array}{l}\text { Rising awareness and common } \\
\text { belief: technology and knowledge } \\
\text { innovation is a key for sustainable } \\
\text { economic growth } \\
\text { Motivation and logics of the } \\
\text { international enterprise: knowledge } \\
\text { innovation and market orientation }\end{array}$ & $\begin{array}{l}\text { The international exchanges } \\
\text { deepened understanding and } \\
\text { belief of the Chinese university in } \\
\text { technology and knowledge innovation } \\
\text { and thus facilitated the } \\
\text { institutional evolution. }\end{array}$ \\
\hline $\begin{array}{l}\text { Stage } 2 \\
\text { Intra-organizational } \\
\text { transformation in } \\
\text { the Chinese } \\
\text { university }\end{array}$ & $\begin{array}{l}\text { Joint R\&D endeavors } \\
\text { between Chinese } \\
\text { universities and industries } \\
\text { start to prosper } \\
\text { University, industry and } \\
\text { government "taking the } \\
\text { role of the other" [68] }\end{array}$ & $\begin{array}{l}\text { Logics of market-oriented } \\
\text { organizational cultures and } \\
\text { process-oriented management culture } \\
\text { in technology innovation }\end{array}$ & $\begin{array}{l}\text { The international enterprises' } \\
\text { increasing approaching to Chinese } \\
\text { research universities accelerated } \\
\text { the government and university to } \\
\text { perfect the corresponding } \\
\text { institutional settings. }\end{array}$ \\
\hline $\begin{array}{l}\text { Stage } 3 \\
\text { Interactions } \\
\text { between Chinese } \\
\text { university and } \\
\text { international } \\
\text { enterprise }\end{array}$ & $\begin{array}{l}\text { Joint R\&D institutes are } \\
\text { created through } \\
\text { interactions between } \\
\text { organizations in the three } \\
\text { sectors ("generating } \\
\text { hybrid organization") } \\
\text { The danger in "taking the } \\
\text { role of the other" }\end{array}$ & $\begin{array}{l}\text { An agreement based on the logic } \\
\text { of knowledge innovation } \\
\text { Disparity in thinking paradigms: } \\
\text { Logics of technology innovation and } \\
\text { market orientation } \\
\text { A salient impact of the logic of } \\
\text { process management } \\
\text { The danger in "taking the role of } \\
\text { the other": logics of market } \\
\text { orientation and process management } \\
\text { Inadequate regulations and } \\
\text { inexperience: logic of IPR } \\
\text { protection } \\
\text { The absent logic of civil society }\end{array}$ & $\begin{array}{l}\text { Service and "catch-up" mentalities } \\
\text { of Chinese university resulted in } \\
\text { the danger in "taking the role of } \\
\text { the other". } \\
\text { The awareness of Chinese } \\
\text { government and universities } \\
\text { about IPR protection was raised in } \\
\text { the process of cooperating with } \\
\text { international industrial partners. } \\
\text { The potential of joint R\&D } \\
\text { institutes to create functional } \\
\text { mechanisms that can coordinate } \\
\text { between top-down control and } \\
\text { bottom-up initiatives. }\end{array}$ \\
\hline
\end{tabular}

\section{Results and Discussion}

The results of this paper examine the institutional development and contextual relevance of a joint $R \& D$ institute co-established by a Chinese research university and an international enterprise. The discussions return to the research question posed in the introduction section of the paper and link the findings from the case back to the analytical framework of Cai's $[62,69]$ institutional orders in the evolution of Triple Helix models. Which mingling institutional logics, respectively carried by Tsinghua 
University and the UTC, affect the collaboration between both parties moving from informal R\&D collaboration toward an institutionalized organization?

\subsection{Stage 1: Realization of the Needs}

\subsubsection{Common Belief: Logics of Technology and Knowledge Innovation}

In the first stage, it has been commonly acknowledged that single organizational sectors alone can no longer respond to changes and uncertainties unless they cooperate with each other [49]. In the circumstances of this study, when China tried to deepen its integration into the global society, we can perceive a rising awareness in universities, industry and government that technology and knowledge innovation is key for sustainable economic growth. This common belief started to grow and enabled the "Triple Helix impetus" [69].

To motivate the universities and enterprises to cooperate with each other, the Chinese government provided regulatory mandates. In 1996, the law on "Promoting the Transformation of Scientific and Technological Achievements" was issued to encourage joint R\&D activities. In 1999, the Ministry of Education launched the "Action Scheme for Invigorating Education in the 21st Century". Within this scheme, the "Project to Stimulate the Industrialization of High-Technology Industry in Universities" was specifically implemented to develop joint R\&D institutes in universities. The visible result in 2000 saw an over $200 \%$ increase in $R \& D$ centers from previous years [6]. China is turning to gain a stronger normative basis for developing the Triple Helix [50]. Both the normative and regulative initiatives lead to the second and the third stages of Triple Helix evolution.

4.1.2. The Motivation of UTC to Work with Tsinghua: Logics of Knowledge Innovation and Market Orientation

UTC has its own in-house research institute. Like most of the in-house research institutes of large enterprises, the UTC research institute is funded by the business units of UTC; the difference is that it supports the organic growth of UTC not only through technology innovation, but also it pays great attention to knowledge and process innovation. Some research fellows of the UTC research institute can go back to academia without an academic gap but possessing advantageous experience working closely with industry. Considering the knowledge innovation capacity of the UTC research institute, why did UTC still need a joint R\&D institute with Tsinghua? It was the then-Director of the UTC research institute who made the decision to work with Tsinghua (Interview THU-UTC 05, 06).

First, UTC considered expanding its market in China. A university-based joint R\&D institute could provide a breakthrough and a solid foundation. Tsinghua was strategically selected as a channel for UTC to get close to the Chinese government, as UTC knew of the governmental resources possessed by Tsinghua (Interview THU-UTC 05, 06). Second, the current tendency in industrial development required UTC to explore the pathway of system solutions in the new architecture of building control. The team of Professor Jiang Yi, from the School of Architecture at Tsinghua, was world-renowned in this field (Interview THU-UTC 05, 06). Third, a joint R\&D institute at Tsinghua could provide high-quality but low-cost researchers. Moreover, research students engaging in joint R\&D projects would become candidates for their talent pool. Some hidden motivations were revealed by a member of the Tsinghua-UTC Center, who was a representative of the UTC side:

Actually, five million US dollars is not a big amount for UTC as a large international enterprise. The cost effectiveness of this venture is very high. It seems like UTC does not have concrete requirements for the center. This is a very smart strategy. The Tsinghua researchers can feel UTC's kindness and flexibility and they are pleased to work on high-quality projects. Moreover, UTC can win some prestige in China from partnering with Tsinghua. With the Center as a window, UTC has gained some added value: it has had opportunities to join Sino-US energy cooperation at the national level. Professor Jiang is a leader of one of the research themes, so UTC can take part in high-profile cooperation through the Tsinghua-UTC 
Center. Professor Jiang has also introduced UTC to governmental agencies including the Ministry of Construction and the MOST. It is crucial for UTC to expand its market shares in China. (Interview THU-UTC 04)

\subsection{Stage 2: Intra-Organizational Transformation in the Chinese University}

In the second stage, each organizational sector "takes the role of the other" (as secondary tasks), but they maintain their distinct identities and perform traditional roles (as primary tasks). In this stage, universities engage in industrial activities, enterprises further strengthen their R\&D capacity, and governments also provide venture capital to help start new enterprises. The institutional logics underlining these changes are market-oriented organizational culture and process-oriented management culture in technology innovation [50].

In the case of Tsinghua, during the process of "taking the role of the other", the Triple Helix actors have respectively realized the need for engaging in each other's fields, but sometimes institutional conditions have not been ready [49].

The Tsinghua leadership took the pioneering initiative to establish the University-Industry Cooperation Committee (UICC) in early 1992, which was partly inspired by the Western experience of managing university-industry R\&D cooperation. In addition, the joint R\&D cooperation between Tsinghua and UTC started in 1995, among many other international joint endeavors. The international exchanges deepened understanding and belief of Chinese universities in technology and knowledge innovation and thus facilitated the institutional evolution.

As a leading science and technology university in China, Tsinghua's international R\&D cooperation with industry is among the top in Chinese research universities, in terms of funding, disciplinary scale, and the qualifications of the international industrial partners [59]. More than 70 percent of Tsinghua's international $\mathrm{R} \& \mathrm{D}$ funds come from international enterprises. The primary pattern of international $R \& D$ cooperation with industry at Tsinghua is joint research projects. Most of the joint R\&D institutes are established and sustained based on projects. The other two forms of international R\&D cooperation with industry are: (1) university-based foundations set up by international enterprises and (2) licensed patents and know-how (Interview THU UA 2).

The business of Tsinghua's joint $R \& D$ institutes is related to three administrative departments: (1) the University-Industry Cooperation Committee (UICC); (2) the Overseas R\&D Management Office (Overseas RDMO); and (3) the International Technology Transfer Center (ITTC) (http://www.kfb. tsinghua.edu.cn/qhw/index.htm (Accessed on 1 December 2019)).

The Tsinghua leaders have always been responsive to national tendencies. Since Xiaoping's call for accelerating economic reform and opening the door to the outside world during his publicized tour to southern provinces in early 1992, intra-organizational transformation has taken place, and organizations in university sectors have tended to be more market oriented [51]. In 1995, Tsinghua took a pioneering initiative among Chinese universities: it established the University-Industry Cooperation Committee (UICC), after then-President Wang Dazhong visited MIT. He was obviously inspired by the Western experience of managing university-industry R\&D cooperation (Interview THU UA 2).

The organizational structure of the UICC is demonstrated in Figure 2: 


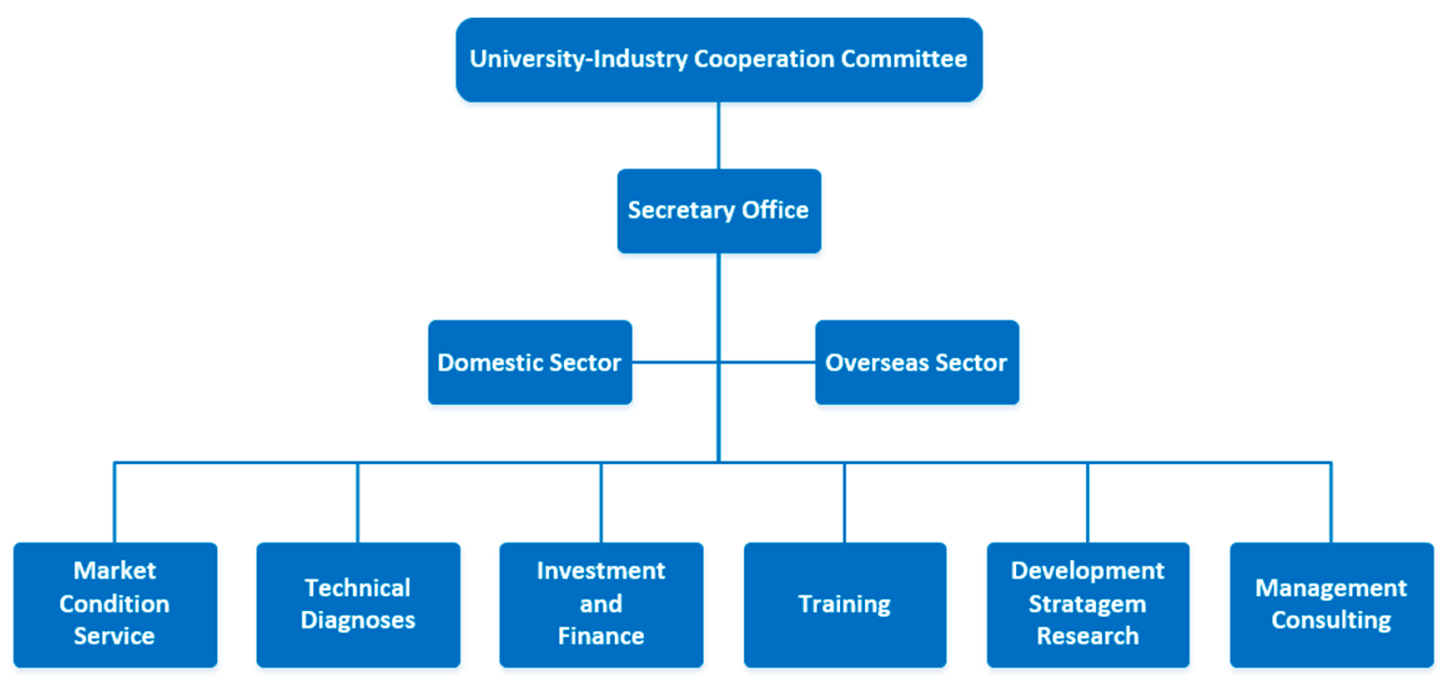

Figure 2. Organizational structure of UICC. Source: http://www.kfb.tsinghua.edu.cn/jgjs/index_jgjs.htm (Accessed on 1 December 2019). Translated and reorganized by the author.

The UICC serves as a platform connecting Tsinghua academia and enterprises. It functions like an enterprise club, accepting domestic and international enterprises as members. The enterprises need to pay an annual membership fee to get access to the events and meetings organized by the UICC. The UICC also helps the member enterprises organize job fairs and set up scholarships, and helps Tsinghua faculty members find industrial partners. Many joint R\&D institutes at Tsinghua are incubated through the UICC's platform (Interview THU UA 02). The UICC serves as a market-oriented door to Tsinghua, as elaborated upon by a representative from an international enterprise member of the UICC:

We are very happy to have such a channel to connect us with Tsinghua. If we need to approach Tsinghua professors and invite them to be consultants for our R\&D activities, it is very difficult to find the right persons. All the Tsinghua teachers are extremely busy. The UICC will do their best to help us find the professors we are looking for or recommend other appropriate candidates. Other than that, if we want to visit any institutes of Tsinghua or find out information about Tsinghua's organizations, they can act as our connection. (Interview IDS01)

After the UICC opens the door for Tsinghua's potential R\&D cooperation with international enterprises, the following step is official negotiation between Tsinghua and international industrial partners. This process is managed by another administrative department, the Overseas R\&D Management Office (Overseas RDMO). The Overseas RDMO manages legal issues, including IPR, contract review, and mid-term and final evaluation. It works closely with the UICC, and has an obvious marketing function. At the university level, the joint $R \& D$ institutes are managed by the Overseas RDMO (Interview THU UA 02).

The third administrative department related to the business of the joint R\&D institutes of Tsinghua is the International Technology Transfer Center (ITTC). Different from the other two departments, the ITTC was established and funded by the government (Interview THU UA 01). In 2001, Tsinghua was authorized by the MOE and the former State Economic and Trade Commission to set up such a technology transfer institute together with five other science and engineering universities. Initiated by the government and integrated into Tsinghua's technology transfer system, the ITTC facilitates Chinese enterprises' international R\&D cooperation, and provides channels for international technologies to be introduced to the Chinese market (International Technology Transfer Center. About us: Profile. Available online: http://www.ittc.com.cn/ittc/english/html/aboutus/profile.asp (accessed on 10 November 2019)). While the other five university technology transfer centers came 
across bottlenecks, the ITTC at Tsinghua runs well. Nevertheless, it also is facing new challenges and demands. As a solution, the Triple Helix sectors need even closer cooperation and interaction $[64,81]$.

The institutional setting for R\&D cooperation between Tsinghua and international enterprises is comparatively mature, although Tsinghua does not have stated strategy and regulation to encourage and regulate such international R\&D cooperation. Tsinghua leadership expects that its researchers can take on a dominant role in initiating and sustaining international R\&D partnerships, rather than always taking the role of serving the large international enterprises by solving their technical problems. Cooperative technical projects can make money, but they do little to create knowledge spillover and contribute to the innovative capacity of the university (Interview THU UA 01).

In addition to UICC, Overseas RDMO and ITTC are functional departments to accelerate and manage the university's engagement with international industrial activities. Together with the ITTC of Tsinghua, the government created technology transfer centers in another five universities, but only the Tsinghua ITTC runs smoothly. Nevertheless, the governmental initiative demonstrates the logics of the market at the state level as well as beliefs in technology innovation as a key to economic growth. On the other hand, the international enterprises' increasing approach to Chinese research universities accelerated the government and university to perfect the corresponding institutional settings.

\subsection{Stage 3: Interactions between Chinese University and International Enterprise}

The joint R\&D cooperation between Tsinghua and UTC started in 1995. After 12 years of partnership, the Tsinghua-UTC Center was established in September 2007. It started with a five-year renewable contract. UTC decided to invest one million US dollars in the Center every year continuously for five years, and the contract was completed by the end of the second five-year term (Interview THU-UTC 05, 06).

4.3.1. The Agreement between Tsinghua and UTC: An Agreement Based on the Logic of Knowledge Innovation

UTC has its in-house research institute with a strong research capacity, and it was the logics of market orientation and process management that drove the UTC to approach Tsinghua: the government resources possessed by Tsinghua could help the UTC to expand its market in China. Moreover, Prof. Jiang's Tsinghua team was one of the top in the field. In the first five years, the UTC demonstrated high respect and patience for knowledge innovation and accumulation.

In the process of building up the partnership, the Tsinghua side was passive (Interview THU UA 01). The final agreement for establishing the joint R\&D institute was a result of both sides' common pursuit of knowledge innovation. Mr. Robert Hobbs, the then-Director of the UTC research institute, sketched a blueprint for the joint venture to persuade Prof. Jiang. He promised sufficient space for knowledge innovation and no interruption from the UTC business units. It is rare for a for-profit industrial organization to make a promise not to request any concrete technology or product innovation from a partnership with a university. Prof. Jiang's Tsinghua team was fascinated by the aim of exploring the new generation of building control systems, and Prof. Jiang assumed the directorship of the Center in the end (Interview THU-UTC 08).

The orientation of the Centre to knowledge innovation amazed some Tsinghua researchers, as described by one of them:

I felt a bit shocked when I joined the Center. I feel that what the enterprises undertake should be closely related to products, and profit is usually the primary goal of enterprises. However, what the enterprise (UTC) proposed is even more forward-looking than the university (Tsinghua). (Interview THU-UTC 08)

\subsubsection{Disparity in Thinking Paradigms: Logics of Technology Innovation and Market Orientation}

Even if Tsinghua and UTC agreed that the research orientation of the Center was forward-looking, their thinking paradigms were disparate: academics are excited about discovering or creating an 
innovative research field that deserves long-time investigation, while industrial people pay more attention to profit generation. Moreover, they may understand a term from different perspectives, as illustrated by a Tsinghua researcher: "At the beginning, we thought the 'cost' they talked about was an economic term. Actually, it implies a more generalized concept, which also includes something of a technological perspective." (Interview THU-UTC 08). The divergence caused difficulty in collaboration, but their interactions also created sparks of innovation.

Although disparity existed, the Tsinghua researchers appreciated that the joint R\&D institute allowed them to work closely with UTC, which had been taking the lead in technology innovation in this field. The Tsinghua researchers valued the market-oriented culture in technology innovation brought by the partnership, as explained by a Tsinghua researcher of the Center:

I feel that many of their suggestions are valuable. They advanced these ideas from the perspective of the industry. They stand at the frontiers of the market and can anticipate the development orientation of the market. When we study a technology or a system, we only focus on how advanced this system or technology is. Rather, they would analyze the cost of using this technology or working out this system. The questions they most frequently ask are: How much money should we input to work out this? What benefits can be obtained from doing this? (Interview THU-UTC 08)

\subsubsection{A Salient Impact: The Logic of Process Management}

The logic of process management brought by Tsinghua's substantive and sustainable partnership with UTC had a salient impact on the processes of knowledge production and technology innovation. It was also important for innovation efficiency [82].

In the first five years, the UTC side designated researchers and project managers from the UTC in-house research institute to be stationed at the Center, and they were paid by the UTC side. This situation was rare among Tsinghua's joint R\&D institutes with enterprises. The UTC staff played multiple roles as project managers, coordinators and also researchers. They had to coordinate different actors from both Tsinghua and UTC. All the UTC staff were Chinese nationals and had relevant disciplinary backgrounds in the research field. They did not have difficulties working with the Tsinghua researchers in terms of professional knowledge (Interview THU-UTC 08).

Nevertheless, the UTC staff positioned themselves clearly, as they were paid by the UTC side. They informed Tsinghua of the ideas and decision of the UTC side, and they were also responsible for reporting the research progress to UTC. Sometimes, they had to reconcile conflicting opinions from different actors (Interview THU-UTC 08). UTC influenced the research process of the Center through these designated staff, as elaborated by one of them:

We would listen to the ideas from both sides. We worked and discussed with the Tsinghua researchers, and we regularly had meetings with our headquarters in the US and listened to their views. Their ideas would affect our thinking. Then, our considerations would also impact the research of the Center. (Interview THU-UTC 08)

The logic of process management therefore infiltrated the Center through these continuous efforts and interactions. The research management style of the UTC staff was apparently different from that of the Tsinghua researchers: at the start of every project, the UTC staff would discuss and confirm the timetable with the Tsinghua research team; they would remind and push the research team before each time node, and the project could not go on to the next step unless the previous task had been verified, as UTC needed to control costs and progress (Interview THU-UTC 08).

On the other hand, the university researchers were comparatively flexible in managing research projects. They had their individual priority lists, and they were multi-tasking. In Chinese research universities, the reality is that industrial research projects are always outranked by governmental projects in the university professional promotion system. Moreover, the Tsinghua researchers were not administratively affiliated with the joint $R \& D$ institute, and they were from different disciplinary 
departments. It was quite challenging for the UTC staff to manage the research process. They tried very hard to build up a sense of belonging and team spirit at the Center, which proved to be effective (Interview THU-UTC 07, 08).

In addition to regular project meetings, a series of formal and casual activities to increase cohesive forces were organized. When necessary, the UTC staff also talked with the researchers individually. By the end of the first five years, most of the Tsinghua researchers identified themselves as "members" of the Center, rather than just "working for" the projects of the Center. They were enthusiastic about joining the research teams, and even proud of being members of the Center. This sense of identity is important for optimizing the institutional environment of joint R\&D institutes, but managing this process is particularly difficult in the context of joint $R \& D$ institutes, and even harder if they conduct interdisciplinary research (Interview THU-UTC 07, 08).

Lang [83] believes that the success of technology innovation in the West is greatly attributed to the culture of process management. It was the culture of process management, among other so-called Western institutional logics, that had the most thorough impact on the Triple Helix relationship through an international joint R\&D institute in two ways. Firstly, UTC, as a for-profit organization, is goal-oriented, without question. However, their patience for knowledge innovation and the trust they provided to the joint endeavor with Tsinghua made it a process-oriented adventure. Lang [83] believes that Chinese practices are more goal-oriented rather than process-oriented. The mentality of being pragmatic leads the Chinese to find shortcuts to outcomes and neglect process management. It is hard to conclude that being pragmatic originates from the country's inherent cultural constraints. Being pragmatic is strategically feasible and necessary in certain periods and conditions. Secondly, the Center embodied the standardized process management of knowledge production, which is a favorable institutional logic, especially in the process of academia and industry "taking the role of the other".

\subsubsection{The Danger in "Taking the Role of the Other": Logics of Market Orientation and Process Management}

The logics of market orientation and process management stand near the core element of the Triple Helix thesis-"taking the role of the other". One of the most important implications of this thesis is that when universities take on the role of industry, they must maintain their core missions of research and teaching, and "the third mission" must be adaptable to the primary ones [84]. Joint R\&D institutes are one of the mechanisms that a research university employs to translate its research findings into use. Etzkowitz [84] warned of the danger of a university mining its innovation store and failing to replenish it because of dependence on short-term commercial gains (Ibid, p. 319). Joint R\&D institutes, as hybrid organizations, are generated as a result of "taking the role of the other". Compared with other university research institutes, the university side of a joint R\&D institute is more likely to run into the danger described by Etzkowitz [84].

In the second five years of the Center, Dr. David E. Parekh took over the role of Mr. Hobbs as director of the Center, which led to structural transformation of the joint R\&D institute. Dr. Parekh felt that the Center had gone too far away from market needs, and it would take too long to see results. Short-term interests were more important than the benefits that might come from long-term knowledge innovation. As a result, the Center shifted to become pragmatic and goal-oriented. UTC asked the Center to generate R\&D outputs that could be easily transferred into products by its business units (Interview THU-UTC 08).

The author of this study argues that, in the context of joint R\&D institutes in China, the danger of "taking the role of the other" is not universities engaging with industry and becoming part of it, as Cai [23] stated; it is the service and "catch-up" mentalities of the Chinese university researchers, which can result in deviating from knowledge innovation. The service mentality is based on the university serving its industrial partners as funders and clients. This happened in the case of the 
Tsinghua-UTC Center, especially in its second five-year term. Consequently, the Tsinghua researchers became outsourced researchers of UTC, identical to those at the UTC research institutes.

The "catch-up" mentality arises when universities partner with world-leading international enterprises like UTC. In the second five-year term, the UTC side progressively intervened in decision-making about the Center's research orientation, and the Tsinghua side tended to make concessions. One of the reasons for this is that the Tsinghua researchers believed that "they [UTC] stand at the frontiers of the market and can anticipate the development orientation of the market" (Interview THU-UTC 08). During the most recent decade, while China's flagship research universities like Tsinghua have grown to be acknowledged worldwide for their knowledge and technology innovation, they have gradually learnt how to get rid of the "catch-up" mentality and maintain equal dialogue with powerful international partners [58].

\subsubsection{Inadequate Regulations and Inexperience: Logic of Intellectual Property Rights Protection}

The Role of Tsinghua Administration

The Tsinghua-UTC Center had been regarded by the Tsinghua administration as a showcase for joint R\&D institutes. As mentioned above, in 2014, the UTC research institute, as a quality international enterprise partner of Tsinghua, was awarded the 2013 Overseas Enterprise Cooperation Award and the 2013 UICC Overseas Cooperation Consultant Award (http://news.carnoc.com/list/280/280533.html (accessed on 10 November 2019, in Chinese)). The quality of a partnership is based on trust between university and industry, and this trust is greatly endorsed by a mature institutional environment for IPR protection [49]. In the case of the Center, both parties were satisfied with the allocation of IPR ownerships, but the institutional environment of China's Triple Helix for IPR protection is far from mature.

As a leading science and engineering university in China, the practices and principles adopted by Tsinghua in handling Triple Helix inter-organizational relations are always followed by other Chinese universities [60]. Therefore, Tsinghua's standpoints on and methods for IPR protection are crucial for optimizing the institutional context of China's Triple Helix linkages. The Overseas RDMO of Tsinghua has taken charge of negotiating with international industrial partners regarding issues of IPR ownership. The Tsinghua administration sticks to the following principles: first, the IPs produced by the joint R\&D institutes affiliated with Tsinghua are owned by the nation. If ownership of the IPRs of the R\&D results produced by Tsinghua researchers is easily taken by international industrial partners, this can be regarded as a loss of national assets, unless both sides can agree on the terms of this ownership; second, the price of IPR ownership must be equal to the real value of the related patents; third, the R\&D products created by Tsinghua researchers need to be highly valued and protected by the university (Interview THU UA 01,02).

However, Tsinghua's disadvantage in dealing with IPR with UTC came from inadequate regulations and inexperience. While the Tsinghua side was willing to transfer their half of the IPR ownership to UTC, this deficiency of the university administration resulted in an unsuccessful result, as described by a Tsinghua researcher of the Center:

In the first five years, each side (Tsinghua and UTC) owned 50 percent of each IP, and both sides had the rights to use these patents produced by the Center. Once, UTC wanted to buy the half (of the IPR) of a patent owned by the Tsinghua side; however, the Overseas RDMO had no idea about the charge. They just randomly set a price of 100,000 US dollars. But UTC deemed it too expensive. The UTC side thought that they had invested one million US dollars every year; the price of 100,000 US dollars was unreasonable. In the end, UTC gave up and both sides did not achieve an agreement. (Interview THU-UTC 06)

This situation was explained by a staff at the Overseas RDMO: 
We are accumulating our experience and learning from foreign institutions. We learned a lot when the headquarters of the UTC research institute invited us to the US. However, our standpoint is different [from those of the university researchers]. We have to balance the benefits of different stakeholders: we need to respect the willingness of the university teachers, consider the benefits to the university, and keep a favorable relationship with the enterprise. We also need to take the issues of law and contract into consideration. (Interview THU UA 2)

The director of the Overseas RDMO was designated by the President of Tsinghua as the legal representative to sign contracts with international industrial partners. Before decision-making, the Overseas RDMO needed to make sure that the international technology transfer would not harm the interests of the nation (Interview THU UA 02).

The service mentality of Tsinghua researchers brought them into a disadvantageous position in terms of IPR ownership negotiations, and such a mentality was common among Tsinghua researchers. They believed that when their international industrial partners paid for joint R\&D projects, and the researchers repaid them with expertise, it was reasonable for the industrial partners to own the IPRs. As a result, the university side easily gave up IPR ownerships in negotiations (Interview THU UA 01,02).

This way of giving up IPR ownerships was opposed by the Tsinghua administration. The Overseas RDMO had been considering measures for IPR ownership distribution. The university side believed that, in principle, an enterprise inputs the funding for a joint R\&D project or invests in establishing a joint $R \& D$ institute, and the R\&D outputs are shared by both sides. However, in many cases, the large international enterprises are stern and insist that the IPRs should be entirely owned by them. As a result, it is often difficult for both sides to reach an agreement. Even though the Tsinghua leadership had set up a principle of IPR ownership sharing, it was not strictly enforced. Tsinghua allowed flexibility for the department and university researchers to judge whether giving up IPR ownerships was worthwhile. However, the Overseas RDMO had set some corresponding measures to restrain such cooperation. It charged high administration fees to joint R\&D projects that gave up the university's IPR ownerships. For example, if the total project budget was one million yuan, the university charged a 250 thousand yuan administration fee. The percentage was much higher than the fee charged to other joint R\&D projects. These fees were used for a university development fund (Interview THU UA 01,02). This countermeasure was explained by a staff member of the Overseas RDMO:

The university allows you to take on these projects, although such undertaking can only make money. However, these projects, compared with those projects which can share the IPRs, have to pay extra administration fees. The university cannot forbid the researchers from conducting these projects, since the university administration cannot judge for the researchers whether these projects are indeed worthwhile or not. But the university does not encourage researchers to conduct the kind of project which loses IPR ownership. Charging an administration fee is meant to indirectly limit the researchers who undertake this kind of cooperation through disadvantaging the benefits of the projects. When the researchers feel the projects are not worth it, they will redirect themselves to other cooperative projects. The university can also use these administration fees as university development funding to improve the university R\&D environment and facilities. We have a series of specific measures [to use the development funding]. (Interview THU UA 02)

The countermeasure implemented by the Tsinghua administration was reasonable. Large international enterprises pay great attention to IPRs; they are clear that it is highly cost-effective to cooperate with Chinese universities, since they can easily own the IPRs with low financial inputs from such R\&D cooperation [85,86]. 
The Change in IPR Ownership Distribution Pattern

As agreed, in the first five years of the Center, every patent was equally owned by both sides. Inventors - in most cases, the Tsinghua researchers of the Center-had the right of authorship to the patents. In the second five years, an unsuccessful case of purchasing IPR ownership partially resulted in UTC's decision to transform the IPR ownership distribution regulation. The more important reason was the shift of the Center's research orientation from knowledge innovation to technology and production innovation. The outputs of the joint research were more likely to be transferred into products (Interview THU-UTC 08).

In the second five years, when Tsinghua and UTC advanced their research topics of interest, the IPRs of the outputs generated from the UTC research topics were entirely owned by the enterprise. This was also applicable to the Tsinghua side. In addition, if UTC was interested in the outputs owned by Tsinghua, Tsinghua needed to sell them to UTC upon agreement on the price. If the patents generated benefits, the inventors could have economic compensation. This transformed distribution regulation was more beneficial to UTC's acquisition of the patents it deemed promising in the market (Interview THU-UTC 07, 08).

As a result, UTC had more authority in the distribution of IPR ownership. In joint R\&D cooperation, large international industrial partners are always more powerful in terms of IPR protection. UTC understood that the Tsinghua administration was inexperienced in dealing with IPR issues, and the university researchers did not really care about the IPR ownerships (Interview THU UA 02). Some of them deemed it to be a wise change:

The pattern of the second five years is better; it is actually troublesome if every patent is jointly owned. It may cause conflict if a patent is going to be transferred to product. Many of us [the Tsinghua researchers] feel that the changed pattern is clearer and more scientific than the one before. It is hard to imagine that when UTC wants to launch a product, it has to get approval from Tsinghua. (Interview THU-UTC 06)

Moreover, the changed pattern made it easier for Tsinghua researchers to publish papers, as elaborated by a Tsinghua researcher of the Center:

In the past five years, if I wanted to publish a paper, the paper needed to be reviewed and approved by UTC. Nowadays, if I publish a paper regarding the research projects allocated to the Tsinghua side, I do not have to get approval from UTC; this truly provides us with more flexibility. (Interview THU-UTC 07)

In the third stage, when interactions between organizations in the three sectors become increasingly intensive, logics of intellectual property turn out to be a key factor in the Triple Helix development, obviously in the case of the Tsinghua-UTC Center. The problem of IPR in China originates from the inadequate reinforcement of patent law [87]. Nevertheless, the awareness of Chinese government and universities about IPR protection was raised in the process of cooperating with international industrial partners. In the past three decades, a dramatic change has taken place in the percentage of invention patents granted in China. In 1990, 70 percent of invention patents granted in China were owned by international actors; this proportion decreased to 50 percent in 2008. From 2009 to 2012, it declined substantially from 49 to 34 percent. In 2017, it became 22 percent. (See Figure 3). Among various reasons for this trend, the intensive interactions between universities and international industrial partners on the platforms of joint R\&D institutes have made a difference. 


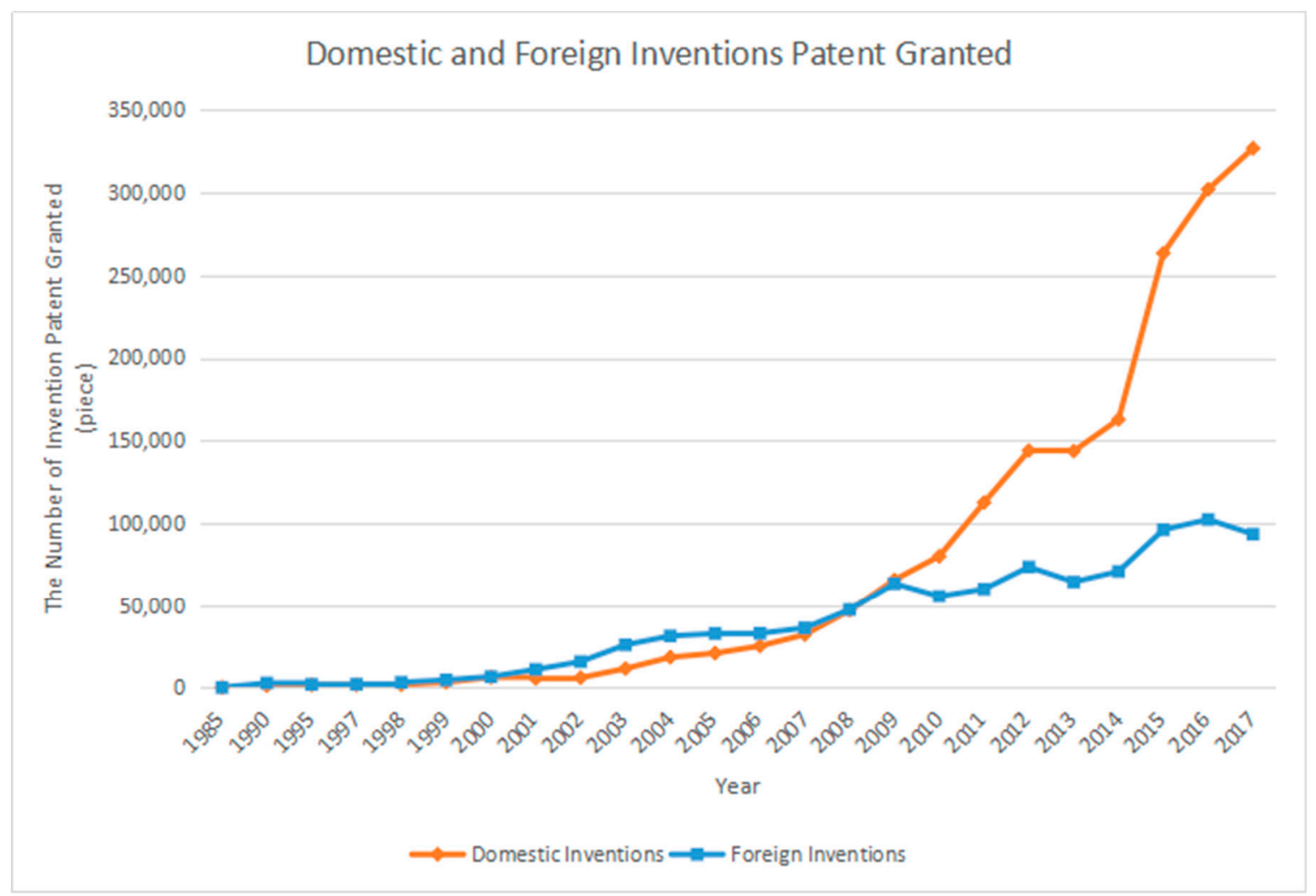

Figure 3. Domestic and foreign invention patents granted (1985-2017). Sources: China Statistical Yearbook 1999-2018 (For example: http://www.stats.gov.cn/tjsj/ndsj/2018/html/CH2015.jpg (accessed on 1 December 2019)).

As for the logics of civil society, which is a Western concept and seems absent in the discourse of the study, the Chinese government lacks effective policy measures to stimulate bottom-up initiatives. Future studies can explore whether the endeavors of joint R\&D institutes have the potential to create functional mechanisms that can coordinate between top-down control and bottom-up initiatives [49].

\subsection{Stage 4: Institutionalization of Joint RED Institute}

In the final stage, to facilitate the institutionalization process, logics of the market competition environment and democracy in policymaking are important in collective sense-making and belief shaping [49]. The joint R\&D institutes provided benefits for international enterprises, including convenient access to governmental resources and the local market. As a result, these advantages may help accelerate their acceptance by the local market, and then reduce the Chinese enterprises' profit margins. Moreover, joint R\&D institutes may also cause a crowding-out effect [16] between international and Chinese enterprises: the deeper the international enterprises' involvement in the university $R \& D$, the less the universities will be in demand to cooperate with Chinese enterprises. This is partly because the university $R \& D$ resources are limited. On the other hand, the enterprises would be concerned about issues of confidentiality if two enterprises in the same field set up joint R\&D institutes at the same university. For example, Huawei Technologies Co. Ltd., which was considering creating a joint R\&D institute with Tsinghua, gave up the plan because of the existence of the Tsinghua-Cisco Lab. Therefore, it has been commonly acknowledged that Chinese enterprises' market competition is insufficient, which has limited their innovation capacity [88]. The joint R\&D institutes can raise the logics of market competition in China's Triple Helix linkages.

Regarding the logics of democracy in policymaking, the relevance of this study can be predicted when major challenges of international $R \& D$ cooperation have raised importance of policy-makers to 
improve the institutional environment of the transnational and national innovation system, including week IP protection, insufficient coordination for competition, and low degree of technology transfer.

\section{Conclusions}

In conclusion, this study discussed the institutional logics generated in the institutionalization process of a joint R\&D institute at a Chinese research university; furthermore, it zoomed in on the ways in which the collision between Western and Chinese institutional logics have affected China's transnational Triple Helix relations. The institutionalization process of joint R\&D institutes results in an increasing difficulty to differentiate Western from local logics. In the Chinese context, some of the so-called Western logics have taken roots: (1) vision and patience in knowledge innovation and (2) beliefs in technology innovation as a key to economic growth [49]. Some have started to sprout: (1) market orientation and market competition; (2) process management; and (3) IPR protection. The others are still largely absent: (1) civil society, and (2) democracy in policymaking.

The Chinese are pragmatic, and they are inclined to find shortcuts to outcomes [83], but this does not necessarily mean they do not have patience in knowledge innovation or that they will ignore process management. Because of the Chinese mentality of being pragmatic and retaining flexibility in various conditions, Chinese people always preserve space for digesting the Western logics that they deem useful and that have proved favorable for economic development.

The most significant policy implication is related to the improvement of patent law. The case of the joint R\&D institute's IPR ownership distribution provided experience and lessons for improvement. China's incomplete IPR legal system is the largest barrier for substantiating the university-industry $R \& D$ cooperation. At the institutional level, the universities need to improve the professionalism of their legal advisory offices. When negotiating with the large international enterprises about IPR ownership distribution issues, the professionals representing the university side need to hold explicit principles and standpoints. This can ensure equal $R \& D$ partnerships. As a result, the university researchers would be more stimulated and confident in participating in joint R\&D institutes as the university's legal section could protect their rights and interests.

Secondly, the policy vacuum in international joint R\&D cooperation needs to be filled. This deserves joint efforts from related governmental agencies (i.e., the Ministry of Science and Technology and the Ministry of Education) and research universities. The experience and lessons from the joint $R \& D$ institutes would be especially valuable for filling in this policy blank. Moreover, science and technology policies can provide specific incentives to attract international enterprises to locate their innovative-oriented $R \& D$ in China. For example, if the government could provide matching funds for international enterprises to locate their technology-intensive and forward-looking $R \& D$ activities in Chinese research universities, the joint R\&D institutes would achieve both financial and human sustainability.

Thirdly, the joint R\&D institutes, with the logics of process management, technology innovation, market orientation, and IPR protection, can serve as experimental bases for completing policy-making related to university technology transfer systems. For example, The law of the People's Republic of China on Facilitating the Transfer of Scientific and Technological Results, revised in 2013, emphasized the connection between R\&D outputs of joint $R \& D$ projects and university professional promotion systems; moreover, it aimed to improve the distribution principles of IPR ownerships. The policy-makers have realized that the disconnection between joint R\&D outputs and university promotion systems has led to the inefficiency of China's innovation system. The joint R\&D institutes can provide a stable and enabling environment to measure the institutional mechanisms that can contribute to an innovation-oriented system.

Finally, the logics of vision and patience in knowledge innovation and process management could resolve the university researchers' "role strain" between governmental and industrial research projects. The governmental research projects enjoy higher scores in the university's professional promotion system and they can generate more publications. The university researchers, especially the junior 
ones, have to allocate more time and energy to governmental projects. In contrast, Su's [89] study in an American context drew a different conclusion from that found in the flagship Chinese research universities: in the United States, affiliation with joint R\&D institutes is more appealing for junior researchers than for tenured faculty members; in the United States, working closely with industry can produce more publications, which is advantageous for professional promotion [89].

The pattern of the Center in the first five years, with its forward-looking and interdisciplinary features, had great potential for generating high-quality publications. Whether and how joint R\&D institutes can contribute to resolving the university researchers' "role strain" between governmental and industrial projects deserves future research.

Author Contributions: Overall research design: J.M.; Data analysis: J.M.; Writing original draft: J.M.; Review and editing: J.M.

Funding: This research was funded by the National Education Sciences "Thirteenth Five-Year Plan" of China, National General Projects in 2019, "Research on the Societal Impact and Assessment Mechanism of International (Regional) Scientific Research Cooperation in Chinese Universities", Grant number: BIA190166.

Acknowledgments: I am highly grateful to the guest editor's and three peer reviewers' constructive and inspiring comments and suggestions, which have greatly helped me to improve the paper. I also appreciate the participants of this research. They provided empirical data and valuable insights, which are the basis of this study.

Conflicts of Interest: The author declares no conflict of Interest.

\section{References}

1. Tijssen, R.; van de Klippe, W.; Yegros, A. Globalisation, Localisation and Glocalisation of University-Business Research Cooperation: General Patterns and Trends in the UK University System; Centre for Global Higher Education: Hawthorn, Australia, 2019.

2. Ma, J. Internationalization of Collaborative Research Units in Chinese Flagship Research Universities: An Academic Perspective on Cross-Border Tiple Helix Linkages. Ph.D. Thesis, The University of Hong Kong, Hong Kong, China, 2015.

3. Meng, D.; Li, X.; Ke, R. Industry-to-University Knowledge Transfer in Ecosystem-Based Academic Entrepreneurship: Case Study of Automotive Dynamics \& Control Group in Tsinghua University. Technol. Forecast. Soc. Chang. 2019, 141, 249-262.

4. Dolan, B.; Cunningham, J.A.; Menter, M.; McGregor, C. The Role and Function of Cooperative Research Centers in Entrepreneurial Universities: A Micro Level Perspective. Manag. Decis. 2019, 57, 3406-3425. [CrossRef]

5. Gibson, E.; Daim, T.U.; Dabic, M. Evaluating University Industry Collaborative Research Centers. Technol. Forecast. Soc. Chang. 2019, 146, 181-202. [CrossRef]

6. Boardman, C.; Denis, G. The New Science and Engineering Management: Cooperative Research Centers as Government Policies, Industry Strategies, and Organizations. J. Technol. Transf. 2010, 35, 445-459. [CrossRef]

7. Dodgson, M. Technological Collaboration in Industry: Strategy, Policy and Internationalization in Innovation; Routledge: Abingdon-on-Thames, UK, 2018.

8. Clark, J. The Role of Cooperative Research Centers in Multi-Scalar Innovation and Economic Development Policy in Canada and the US. In Cooperative Research Centers and Technical Innovation; Springer: New York, NY, USA, 2013; pp. 275-291.

9. Davis, D.D.; Janet, L.B.; Julia, Z. Leadership Relationships between Center Directors and University Administrators in Cooperative Research Centers: A Multilevel Analysis. In Cooperative Research Centers and Technical Innovation; Springer: New York, NY, USA, 2013; pp. 149-173.

10. Boardman, C.; Denis, O.G.; Drew, R. Cooperative Research Centers and Technical Innovation: Government Policies, Industry Strategies, and Organizational Dynamics; Springer Science \& Business Media: New York, NY, USA, 2012.

11. Azagra-Caro, J.M.; Robert, J.W.T.; Elena, M.T.; Alfredo, Y.-Y. University-Industry Scientific Production and the Great Recession. Technol. Forecast. Soc. Chang. 2019, 139, 210-220. [CrossRef]

12. Clark, B.R. Creating Entrepreneurial Universities: Organizational Pathways of Transformation; Issues in Higher Education; ERIC: New York, NY, USA, 1998. 
13. Collinson, S.; Liu, Y. Recombination for Innovation: Performance Outcomes from International Partnerships in China. RED Manag. 2019, 49, 46-63.

14. Cheng, Y.; Yun, L.; Wei, F.; Zhe, Y.; Ye, X. Triple Helix on Globalization: A Case Study of the China International Nanotech Innovation Cluster. Inf. Dev. 2019, 35, 272-289. [CrossRef]

15. Zhong, W.; Wei, M.; Xie, Y. Analysis of the Innovation Model of Industry-University-Research Cooperation Technology. China Soft Sci. 2009, 8, 174-181. (In Chinese)

16. Lundin, N.; Sylvia, S.S. Globalization of RED and China: Empirical Observations and Policy Implications; IFN Working Paper; Research Institute of Industrial Economics (IFN): Stockholm, Sweden, 2007.

17. Hou, B.; Hong, J.; Chen, Q.; Shi, X.; Zhou, Y. Do Academia-Industry R\&D Collaborations Necessarily Facilitate Industrial Innovation in China? Eur. J. Innov. Manag. 2019, 22, 717-746.

18. Sun, Y.; von Zedtwitz, M.; Denis, F.S. Global RED in China; Routledge: Abingdon-on-Thames, UK, 2013.

19. Li, J.; Li, Z. Analysis of R\&D Cooperation between Multinational Enterprises and Chinese Universities. Sci. Technol. Manag. Res. 2005, 9, 67-69. (In Chinese)

20. National Bureau of Statistics of the People's Republic of China. Statistical Communiqué of the 2017 National Economic and Social Development of the People's Republic of China; National Bureau of Statistics: Beijing, China, 2017. (In Chinese)

21. Huang, F. International Science and Technology Cooperation Management Initiatives and Exchanges in Universities and Inspirations. Res. Sci. Technol. Manag. 2015, 23, 102-107. (In Chinese)

22. Wang, Z.; Zhao, S.; Chen, T. Research on the External Economic Relations of Chinese Universities; Peking University Publishing House: Beijing, China, 2005. (In Chinese)

23. Xue, L. Universities in China's National Innovation System. Presented at the United Nations Educational, Scientific, and Cultural Organization's Online Forum on Higher Education, Research, and Knowledge, Budapest, Hungary, 20 November 2006.

24. Cong, Z.; Lan, X. A Multinational Integrated Innovation Model Based on Technology and Market. China China Soft Sci. 2003, 2, 108-112. (In Chinese)

25. He, N. Research Institute of Chinese Universities and Multinational Corporations. Master's Thesis, Tsinghua University, Beijing, China, 2006. (In Chinese).

26. Dzisah, J.; Henry, E. Triple Helix Circulation: The Heart of Innovation and Development. Int. J. Technol. Manag. Sustain. Dev. 2008, 7, 101-115. [CrossRef]

27. Serger, S.S.; Magnus, B. China's Fifteen-Year Plan for Science and Technology: An Assessment. In Asia Policy; The National Bureau of Asian: Stockholm, Sweden, 2007; pp. 135-164.

28. Von Zedtwitz, M. Managing Foreign R\&D Laboratories in China. RED Manag. 2004, 34, 439-452.

29. Liu, F.-C.; Denis, F.S.; Sun, Y.; Cao, C. China's Innovation Policies: Evolution, Institutional Structure, and Trajectory. Res. Policy 2011, 40,917-931. [CrossRef]

30. Lin, L.; He, S.; Zhu, X. Significance and Reflection on the Evaluation of Scientific and Technological Innovation. Chin. J. Sci. Technol. Period. 2015, 26, 191-197. (In Chinese)

31. Huang, Y.; Zhang, C. Research on the Cooperation of Science and Technology Innovation between Chinese Research Universities and Multinational Enterprises in the Context of Globalization. Sci. Technol. Manag. Res. 2018, 38, 138-144. (In Chinese)

32. Gugler, P.; Julie, M. Internationalization of R\&D Activities: The Case of Swiss Mnes. Int. Bus. Econ. Res. J. IBER 2010, 9. [CrossRef]

33. Wright, M.; Bart, C.; Andy, L.; Mirjam, K. Mid-Range Universities' Linkages with Industry: Knowledge Types and the Role of Intermediaries. Res. Policy 2008, 37, 1205-1223. [CrossRef]

34. Mowery, D.C.; Bhaven, N.S. The Bayh-Dole Act of 1980 and University-Industry Technology Transfer: A Model for Other Oecd Governments? J. Technol. Transf. 2004, 30, 115-127. [CrossRef]

35. Zhang, H.; Cui, X. An Empirical Study on Factors Influencing Technology Spillovers in R\&D Cooperation between Multinational Corporations and Chinese Universities. Ind. Technol. Econ. 2013, 32, 126-133. (In Chinese)

36. Li, L.Q.; Xin, K.; Pucik, V.; Wei, W.X. Mncs' R\&D Talent Management in China: Aligning Practices with Strategies. Chin. Manag. Stud. 2019, 13, 1086-1106.

37. Kang, W.; Zhao, S.; Song, W.; Zhuang, T. Triple Helix in the Science and Technology Innovation Centers of China from the Perspective of Mutual Information: A Comparative Study between Beijing and Shanghai. Scientometrics 2019, 118, 921-940. [CrossRef] 
38. Liu, Y.; Deng, P.; Wei, J.; Ying, Y.; Tian, M. International R\&D Alliances and Innovation for Emerging Market Multinationals: Roles of Environmental Turbulence and Knowledge Transfer. J. Bus. Ind. Mark. 2019, 34, 1374-1387.

39. Li, S.; Ilan, A. China's Intellectual Property Rights Provocation: A Political Economy View. J. Int. Bus. Policy 2019. [CrossRef]

40. Bruneel, J.; d'Este, P.; Ammon, S. Investigating the Factors That Diminish the Barriers to University-Industry Collaboration. Res. Policy 2010, 39, 858-868. [CrossRef]

41. Zhu, X.; Xu, J. Impact of Knowledge Spillover on the Knowledge Transfer Performance in China's Manufacturing Industry. Technol. Anal. Strateg. Manag. 2019, 31, 1199-1212. [CrossRef]

42. Ghio, N.; Massimiliano, G.; Cristina, R.-L. The Creation of High-Tech Ventures in Entrepreneurial Ecosystems: Exploring the Interactions among University Knowledge, Cooperative Banks, and Individual Attitudes. Small Bus. Econ. 2019, 52, 523-543. [CrossRef]

43. Li, J. Research on R\&D Cooperation between Multinational Corporations and Chinese Universities. Master's Thesis, Tsinghua University, Beijing, China, 2005. (In Chinese).

44. Guo, Y.; Gang, Z. How Do Firms Upgrade Capabilities for Systemic Catch-up in the Open Innovation Context? A Multiple-Case Study of Three Leading Home Appliance Companies in China. Technol. Technol. Forecast. Soc. Chang. 2019, 144, 36-48. [CrossRef]

45. Zhan, B. Analysis of the R\&D Investment Effect of Multinational Corporations in China. World Econ. Res. 2003, 10, 48-53. (In Chinese)

46. Scott, W.R.; Micheael, W.K.; Manuelito, B.; Laurel, S. Introduction. In Higher Education and Silicon Valley; Richard, S., Michael, W.K., Eds.; Johns Hopkings University Press: Baltimore, MD, USA, 2017.

47. Cai, Y.; Borja, R.F.; Jose, L.M.L. Building University-Industry Co-Innovation Networks in Transnational Innovation Ecosystems: Towards a Transdisciplinary Approach of Integrating Social Sciences and Artificial Intelligence. Sustainability 2019, 11, 4633. [CrossRef]

48. Meyer, J.W.; Brian, R. Institutionalized Organizations: Formal Structure as Myth and Ceremony. Am. J. Sociol. 1977, 83, 340-363. [CrossRef]

49. Cai, Y. Implementing the Triple Helix Model in a Non-Western Context: An Institutional Logics Perspective. Triple Helix 2014, 1. [CrossRef]

50. Cai, Y. What Contextual Factors Shape “Innovation in Innovation"?Integration of Insights of the Triple Helix and the Institutional Logics Perspective. Soc. Sci. Inf. 2015, 54, 299-326. [CrossRef]

51. Bhattacharya, S.; Praveen, A. Industrial Linkages in Indian Universities: What They Reveal and What They Imply? Scientometrics 2007, 70, 277-300. [CrossRef]

52. Thornton, P.H.; William, O.; Michael, L. The Institutional Logics Perspective: A New Approach to Culture, Structure, and Process; Oxford University Press on Demand: Oxford, UK, 2012.

53. Yin, R.K. Applications of Case Study Research; Sage: Los Angeles, CA, USA; London, UK; New Delhi, India; Singapore; Washington DC, USA, 2011.

54. Yin, R.K. Case Study Research and Applications: Design and Methods; Sage Publications: Los Angeles, CA, USA; London, UK; New Delhi, India; Singapore; Washington DC, USA, 2017.

55. Sá, C.M.; Anatoly, O. Between the Local and the Global: Organized Research Units and International Collaborations in the Health Sciences. High. Educ. 2011, 62, 367-382. [CrossRef]

56. Rong, Y.U. The Development of Organized Research Units and Its Influences on American Research Universities. Tsinghua J. Educ. 2011, 4, 13.

57. Gray, D.O.; Craig, B.; Drew, R. The New Science and Engineering Management: Cooperative Research Centers as Intermediary Organizations for Government Policies and Industry Strategies. In Cooperative Research Centers and Technical Innovation; Springer: New York, NY, USA, 2013; pp. 3-33.

58. Xie, M. Living with Internationalization: The Changing Face of the Academic Life of Chinese Social Scientists. High. Educ. 2018, 75, 381-397. [CrossRef]

59. Yang, R.; Anthony, W. A World-Class University in China? The Case of Tsinghua. High. Educ. 2012, 63, 645-666. [CrossRef]

60. Yang, R. Advanced Global Strategy in China: The Case of Tsinghua. In Higher Education in the Asia-Pacific; Springer: Dordrecht, The Netherlands, 2011; pp. 143-159.

61. Pang, L. How Tsinghua Became a World Class Research University: A Case Study on the Impact of Rankings on a Chinese Higher Education Institution. Ph.D. Thesis, University of Bridgeport, Bridgeport, CT, USA, 2018. 
62. Etzkowitz, H.; Loet, L. The Dynamics of Innovation: From National Systems and "Mode 2" to a Triple Helix of University-Industry-Government Relations. Res. Policy 2000, 29, 109-123. [CrossRef]

63. Etzkowitz, H. The Triple Helix of University-Industry-Government: Implications for Policy and Evaluation; Swedish Institute for Studies in Education and Research: Stockholm, Sweden, 2002.

64. Etzkowitz, H.; Zhou, C. The Triple Helix: University-Industry-Government Innovation and Entrepreneurship; Routledge: Abingdon-on-Thames, UK, 2017.

65. Thornton, P.H.; William, O. Institutional Logics and the Historical Contingency of Power in Organizations: Executive Succession in the Higher Education Publishing Industry, 1958-1990. Am. J. Sociol. 1999, 105, 801-843. [CrossRef]

66. Cai, Y.; Han, Z.; Rómulo, P. Institutionalization of Technology Transfer Organizations in Chinese Universities. Eur. J. High. Educ. 2015, 5, 297-315. [CrossRef]

67. Cai, Y. Enhancing Context Sensitivity of the Triple Helix Model: An Institutional Logics Perspective. Presented at the The Triple Helix XI International Conference, London, UK, 8-10 July 2013.

68. Etzkowitz, H. The Triple Helix: University-Industry-Government Innovation in Action; Routledge: London, UK; New York, NY, USA, 2008.

69. Zhou, C. Emergence of the Entrepreneurial University in Evolution of the Triple Helix: The Case of Northeastern University in China. J. Technol. Manag. China 2008, 3, 109-126. [CrossRef]

70. Li, M.; He, L.; Zhao, Y. The Triple Helix System and Regional Entrepreneurship in China. Entrep. Reg. Dev. 2019. [CrossRef]

71. Cai, Y.; Cui, L. The Roles of Universities in Fostering Knowledge-Intensive Clusters in Chinese Regional Innovation Systems. Sci. Public Policy 2015, 42, 15-29. [CrossRef]

72. Liu, C.; Cai, Y. Triple Helix Model and Institutional Logics in Shenzhen Special Economic Zone. Sci. Public Policy 2018, 45, 221-231. [CrossRef]

73. Organisation for Economic Co-operation and Development. Oecd Reviews of Innovation Policy China; Organisation for Economic Co-operation and Development: Paris, France, 2008.

74. Geiger, R.L. Knowledge and Money: Research Universities and the Paradox of the Marketplace; Stanford University Press: Stanford, CA, USA, 2004.

75. Etzkowitz, H. Innovation in Innovation: The Triple Helix of University-Industry-Government Relations. Soc. Sci. Inf. 2003, 42, 293-337. [CrossRef]

76. Balzat, M.; Horst, H. Recent Trends in the Research on National Innovation Systems. J. Evol. Econ. 2004, 14, 197-210. [CrossRef]

77. Shinn, T. The Triple Helix and New Production of Knowledge: Prepackaged Thinking on Science and Technology. Soc. Stud. Sci. 2002, 32, 599-614. [CrossRef]

78. Cooke, P. Regional Innovation Systems: Competitive Regulation in the New Europe. Geoforum 1992, 23, 365-382. [CrossRef]

79. Cai, Y. From an Analytical Framework for Understanding the Innovation Process in Higher Education to an Emerging Research Field of Innovations in Higher Education. Rev. High. Educ. 2017, 40, 585-616. [CrossRef]

80. Jan, Y.; Li, Y.; Rogers, J.; Philip, S. Institutionalization of International University Research Ventures. Res. Policy 2017, 46, 1692-1705.

81. Ranga, M.; Henry, E. Triple Helix Systems: An Analytical Framework for Innovation Policy and Practice in the Knowledge Society. In Entrepreneurship and Knowledge Exchange; Routledge: London, UK, 2015; pp. 117-158.

82. Benner, M.J.; Michael, T. Process Management and Technological Innovation: A Longitudinal Study of the Photography and Paint Industries. Adm. Sci. Q. 2002, 47, 676-707. [CrossRef]

83. Lang, X. Lang Xianping'Review: Who Kills Chinese Economy-The Culture Curse on Chinese; Oriental Publisher: Beijing, China, 2009.

84. Etzkowitz, H. The New Visible Hand: An Assisted Linear Model of Science and Innovation Policy. Sci. Public Policy 2006, 33, 310-320. [CrossRef]

85. Jin, J.; Wang, Y.; Wim, V. Patterns of R\&D Internationalisation in Developing Countries: China as a Case. Int. J. Technol. Manag. 2014, 64, 276-302.

86. Zhou, Y.; Tim, M. Building Global Products and Competing in Innovation: The Role of Chinese University Spin-Outs and Required Innovation Capabilities. J. Technol. Manag. 2014, 64, 180-209. [CrossRef] 
87. Massey, J.A. The Emperor Is Far Away: China's Enforcement of Intellectual Property Rights Protection, 1986-2006. Chin. J. Int. 2006, 7, 231.

88. Wang, H.; Li, Y. A Diagnosis of China's Technological Innovation System. Tech. Monit. 2013, 1, 30-35.

89. Su, X. Academic Scientists' Affiliation with University Research Centers: Selection Dynamics. Res. Policy 2014, 43, 382-390. [CrossRef] 